
the Winnipeg Urban Aboriginal Strategy

Mai Nguyen

Department of Political Science, York University

aboriginal policy studies Vol. 3, no. 1\&2, 2014, pp. 54-87

This article can be found at:

http://ejournals.library.ualberta.ca/index.php/aps/article/view/17474

ISSN: $1923-3299$

Article DOI: http://dx.doi.org/10.5663/aps.v3i1-2.17474

aboriginal policy studies is an online, peer-reviewed and multidisciplinary journal that publishes original, scholarly, and policy-relevant research on issues relevant to Métis, non-status Indians and urban Aboriginal people in Canada. For more information, please contact us at apsjournal@ualberta.ca or visit our website at www.ualberta.ca/nativestudies/aps/. 


\title{
Building Relationships or Building Roadblocks? A Look at the Winnipeg Urban Aboriginal Strategy
}

\author{
Mai Nguyen \\ Department of Political Science, York University
}

\begin{abstract}
Do Aboriginal-state public consultations allow for the effective participation of Aboriginal participants in the democratic process, given the group's political marginalization? This paper argues that public consultations are an effective tool for ensuring the successful participation of Aboriginal groups when the consultation process includes mechanisms for redistributing power from governments to stakeholders. Specifically, this paper looks at the federal government's current Urban Aboriginal Strategy (UAS) in Winnipeg. Although the direction and tone of the UAS is set by the federal government, the members of the Steering Committee, composed of twelve Aboriginal members and three government officials, are the ones who decide which policies and programs will receive funding. Decision-making is done through ongoing consultation with the Steering Committee and the Aboriginal community at large. Employing ideas in Arnstein (1969) and public consultations literature to create an evaluation framework, this paper identifies critical components that must be present for consultations to be fruitful. And, based on interviews with the Steering Committee, it finds that the UAS in Winnipeg is a successful mechanism for enabling the effective participation of Aboriginal participants in the democratic process-a process which is resulting in the construction of a renewed Aboriginal-state political relationship.
\end{abstract}

\section{Introduction}

Exercises in participatory democracy are becoming the norm in advanced industrialized countries, with governments consulting and engaging with their citizens in many policy fields. Citizens are no longer limited to going to the election polls every four years and casting a ballot, but are finding new and innovative ways to voice their opinions and be heard. This is especially the case for Aboriginal-state relations in Canada. In Canada, Aboriginal peoples are charting new courses of action for their destinies based on Aboriginal rights provisions enshrined in the Constitution Act, 1982. Since the passing of the act, Aboriginal peoples have made great political and socio-economic strides, including land claims settlements, self-government arrangements, a National Day of Action, attainment of the court-mandated "duty to consult" and, more recently, the Idle No More movement, which has demanded the federal government sit at the table with Aboriginal leaders in Canada. Whether or not Idle No More will result in a renewed relationship is still to be determined, but it does signify that Aboriginal peoples will no longer passively allow governments to make decisions on their behalf.

This paper focuses on one strain of the participatory democracy literaturepublic consultations - and applies it to one segment of the Canadian population: urban 
Aboriginal peoples. The public consultation literature argues that consultations can only be meaningful when mechanisms for effective participation are in place; if they are not, the process is rendered futile and frustrating for participants (Arnstein 1969). Effective participation is the redistribution of decision-making power from power holders to stakeholders, which aids in building relationships based on trust and respect amongst parties. The question this paper asks is: do Aboriginal-state public consultations allow for the effective participation of Aboriginal participants in the democratic process, given the group's political marginalization? If yes, what elements and criteria must be evident for this to be the case? If no, what renders the process ineffective? As a corollary, if consultations are a mechanism for empowerment, what should the government's role be in facilitating consultation? Aboriginal peoples cannot achieve a state of empowerment alone, given their historical marginalization. However, it is not a matter of the government doing the work for Aboriginal peoples and their communities; rather, it requires government to equip Aboriginal participants with the resources necessary to become fully engaged and meaningful participants.

Using the Urban Aboriginal Strategy (UAS) in Winnipeg as a case study, this paper aims to answer these questions by developing a framework for analysis derived from the literature on public consultations and applying it to this urban Aboriginal case. Based on the literature, the author created a series of interview questions and gave them to UAS Steering Committee members (see Appendix A). Urban Aboriginal peoples pose an interesting case study because there is a gap in the Aboriginal-state public consultation literature where urban setting discussions should be. Research tends to focus on resource development, construction-related proposals, and self-government arrangements for nation- and landbased groups (Walker 2005, 396), and has been a by-product of the privileged place nonurban Aboriginal rights occupy in the eyes of the federal government. Little has been written about Aboriginal-state consultations that take place in an urban setting. The research conducted here attempts to fill this gap.

\section{Background}

In 1997, the federal government established the UAS to address the challenges facing the growing number of Aboriginal peoples living in urban centres. In Winnipeg, the UAS originally began as part of the city's larger urban Aboriginal strategy, the Winnipeg Partnership Agreement (WPA). The WPA was signed in May 2004, and represented "a five-year, $\$ 75$ million commitment by the governments of Canada, Manitoba and Winnipeg to strengthen neighbourhoods, promote economic development and enable Aboriginal citizens to fully participate in Winnipeg's economic and social opportunities" (WD 2008). Within the WPA, the objective of the UAS was to "promote self-reliance and increase life choices for Aboriginal peoples in urban centres" by focusing on three priority areas: improving life skills; promoting job training, skills, and entrepreneurship; and supporting Aboriginal women, children, and families (AANDC 2011, i). This was to be achieved by establishing greater internal coordination of federal activities and stronger 
intergovernmental cooperation, and by the forging of relationships between the UAS chapter, the three levels of government, and the urban Aboriginal community (AANDC 2011).

The UAS was announced in 1997, yet no real funding was allocated to the project until 2003, when $\$ 50$ million was dedicated to the project over a four-year period (AANDC 2011, i). Under the UAS, the Office of the Federal Interlocutor (OFI) is responsible for implementing its strategy in designated chapters across the country: Vancouver, Prince George, Lethbridge, Calgary, Edmonton, Prince Albert, Regina, Saskatoon, Thompson, Winnipeg, Thunder Bay, Toronto, and Ottawa. Once actual funding was dedicated in 2003, UAS Steering Committees across the country began holding extensive consultations with their respective Aboriginal communities. The goal of these community consultations, referred to as community forums, was to assist in designing local strategies that would involve partnering with other governments, community organizations, and Aboriginal peoples to support projects that responded to local priorities (MVUAS 2010).

In March 2007, the UAS was renewed for another five years, with a projected annual funding of $\$ 13.7$ million per year (AANDC 2011, i), and was moved from being a pilot project to a government programme. In March 2012, the federal government committed another \$27 million over a two-year renewal period. Funding for this programme has not seen major cuts in an era of economic uncertainty and government cutbacks, which seems promising for the future of the UAS. As an OFI representative stated, "The mentioning of the UAS in the budget demonstrates that the UAS is here to stay-whatever we're doing is positive" (Aboriginal Strategic Planning Committee [ASPC] meeting with author present, April 2012). However, this study is not concerned with policy outcomes and the effectiveness of such outcomes, per se, but with evaluating the Aboriginal-state consultation process itself. Using the framework below and relying on qualitative data conducted through interviews, this paper will reveal the importance of several key factors and characteristics that need to be established in order for Aboriginal-state consultations to be fruitful.

\section{Methodology}

\section{The Interviews}

Winnipeg is an appropriate unit of analysis because of its large urban Aboriginal population, which makes up over 10 percent of the overall population and provides the local UAS chapter with a larger representational pool of members to choose from, as compared to other cities. The data presented here is based upon information in official government documents collected since the UAS's inception, and upon face-to-face personal interviews conducted by the author with Steering Committee members. Steering Committees are volunteer-based (except for government representatives), and generally consist of fifteen participants-ten from the Aboriginal community and five government members (two for the federal government, consisting of one vote, one for the provincial government, and two for the City of Winnipeg, also consisting of one vote). Each member sits on various 
sub-committees (i.e., the selection committee, the community engagement committee), one or two members will assume the position of Chair and/or Co-Chair, one member is appointed as the national caucus representative, and each member represents one vote at the consultation table.

In Winnipeg, personal interviews were carried out with each individual Steering Committee member and all government representatives (see Table 1). Fifteen interviews were conducted and, in two of those sessions, two people were interviewed at the same time. These double interviews were conducted in an effort to save the respondents' time, and were appropriate given that the respondents represented the same level of government and shared one vote at the consultation table. Interviews lasted between sixty and ninety minutes. All recent members of the Winnipeg chapter were personally interviewed at their place of work (except for two interviews that were conducted by phone, and for one member who did not answer any correspondence, see Appendix 2), and answered a series of questions (see Appendix 1). There were nine Aboriginal community representatives, including one youth representative and one co-chair, and all three levels of government were represented, including two from OFI (regional director and development officer), one from the Government of Manitoba, and two from the Government of Winnipeg (a rotating seat that has only one vote). Two former members were interviewed but were no longer participating in the UAS by the time all the interviews were completed.

TABLE 1: Number of Interviews by Participant Category - Winnipeg

\begin{tabular}{|c|c|c|c|c|}
\hline Community & $\begin{array}{l}\text { \# of Interviews with } \\
\text { Federal Government } \\
\text { Representatives, } \\
\text { past and present }\end{array}$ & $\begin{array}{l}\text { \# of Interviews with } \\
\text { Provincial and } \\
\text { Municipal } \\
\text { Government } \\
\text { Representatives }\end{array}$ & $\begin{array}{c}\text { \# of Interviews with } \\
\text { Aboriginal } \\
\text { Community } \\
\text { Members, } \\
\text { past and present }\end{array}$ & Total \# of Interviews \\
\hline Winnipeg & 3 & 3 & 9 & 15 \\
\hline
\end{tabular}

All interviewees were full-time employees of an Aboriginal organization, private organization (Manitoba Hydro), or one of the three levels of government at the time of the interview. All members, including government representatives, are actively engaged in the community either through employment with an Aboriginal organization or as volunteers on Aboriginal-based committees. The youngest member was twenty-one years old, but the majority of members were middle-aged, with long histories of involvement with the Aboriginal community in Winnipeg. Aboriginal members come from different Aboriginal backgrounds, and many are from second- or third-generation urban residences, suggesting the members have deep roots in the community and are invested in the success of the UAS. 


\section{Evaluation Framework}

Given the social, economic, and political alienation of Aboriginal peoples in Canadian life historically, it is important to evaluate whether the public consultations process is able to bridge the trust gap between governments and Aboriginal communities. This paper attempts to evaluate the UAS consultation process through the development of an Aboriginal-specific framework (see Table 2) by employing Arnstein's "A Ladder of Citizen Participation" (1969) as a benchmark, and by extracting various criteria from the public consultation literature. This framework is designed, in general, to determine whether the UAS allows for the effective participation of Aboriginal participants by asking questions related to it. The framework is set up to look at three important components of the consultation process: developmental, empowerment, and relationship building. Each component has a set of criteria that measures effectiveness in terms of redistributing power from, and building trust between, the parties.

TABLE 2: Evaluation Framework

Component

1. Developmental

2. Empowerment

3. Relationship-Building

\section{Criteria}

a) Deciding consultation mechanism

b) Deciding subject matter

a) Deciding representatives

b) Availability of resources and training provided

c) Communication process

a) Political will

b) Use of input

\section{Developmental Component}

The developmental component ultimately sets the agenda. At this stage of the framework, the two questions that need to be asked are: Which party is empowered to decide the purpose and form of consultation, Aboriginal participants or the state? Do Aboriginal peoples have a voice in determining the subject matter for consultation and the form to be employed?

Arnstein writes, "participation without redistribution of power is an empty and frustrating process for the powerless. It allows the power-holders to claim that all sides 
were considered, but makes it possible for only some of those sides to benefit. It maintains the status quo" $(1969,216)$. Her typology classifies eight rungs on "a ladder of citizen participation" (see Figure 1). The first two rungs, manipulation and therapy, are labeled as "nonparticipation," in which the objective of public participation is not to enable participation but allow power holders to "educate" or "cure" the participants. There is no mechanism for participant input on these rungs. Rungs three to five, informing, consulting, and placation, progress to levels of "tokenism" in which participants hear and are heard, but lack the power to affect outcomes. The highest three rungs, partnership, delegated power, and citizen control, progress to varying degrees of citizen power. Partnership allows participants to negotiate and engage in trade-offs with policy-makers, while delegated power and citizen control allow have-not participants a large share of the decision-making authority or full managerial power (217). Arnstein argues that effective participation requires the redistribution of power from power holders to participants, and only then are mechanisms for citizen participation effective (216).

FIGURE 1: A Ladder of Citizen Participation

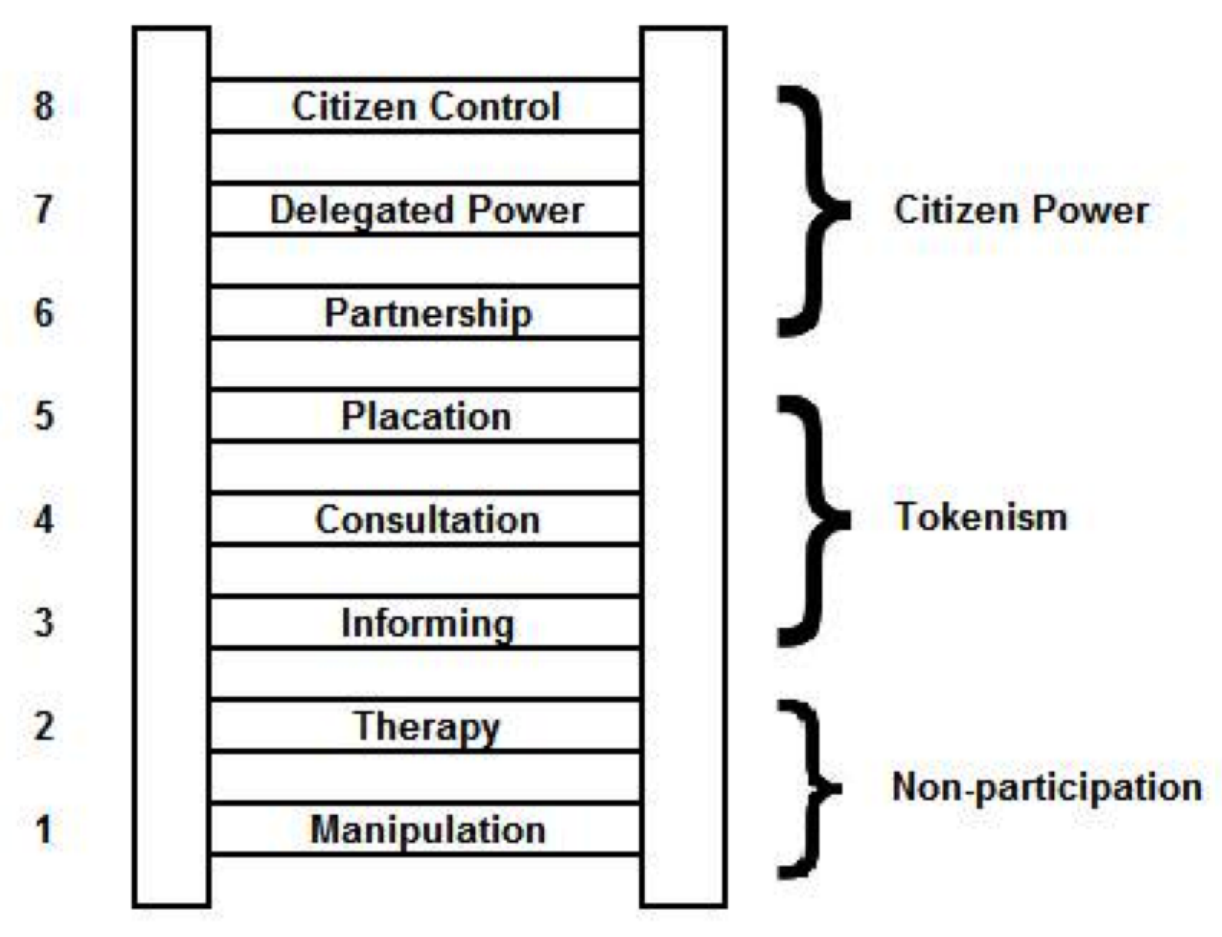

Similarly, according to Atkinson and Willis (2005), the importance of this feature in any consultation process is the very fact that community life is complex, with differing socioeconomic and political environments in which there is no single solution that will suit all communities (4). The authors argue that this "highlights how important it is to ensure 
that communities identify their own agendas for capacity building rather than receiving instructions or aims that are parachuted in and which then may have little legitimacy or community 'voice' to back them" (4). If this does not occur, it can render the consultation process ineffective.

King, Simrell, Feltey, and Susel (1998) bring up this point in their own research, and note that many efforts at public consultations are ineffective and unauthentic due to what the authors call the "practitioner-client hierarchy", in which decision-making, agenda-setting, and gate-keeping authority remains in the hands of the administrator (320). According to the authors, for effective participation to take place, participants must have "the ability and the opportunity to have an impact on the decision-making process" (320), including issue-framing and decision-making. Participation at this stage of the process demonstrates willingness by power holders (governments) to negotiate the terms and conditions of the process, and to reallocate some degree of power to those stakeholders who now possess the ability to make process decisions. As King et al. state,

Effective, or authentic, public participation implies more than simply finding the right tools and techniques for increasing public involvement in public decisions. Authentic public participation, that is participation that works for all parties and stimulates interest and investment in both administrators and citizens, requires rethinking the underlying roles of, and relationship between, administrators and citizens (317).

However, reframing the administrator-citizen relationship will not ensure that effective participation occurs. There are barriers to effective participation that must be overcome on both the administrative and citizen side. King et al. go on to list the barriers which include: the nature of life in contemporary society, administrative processes, and current practices and techniques of participation (322).

Arnstein adds to this list and argues that these roadblocks occur on both the administrative and citizen side, stating,

[o]n the powerholders' side, they include racism, paternalism, and resistance to power redistribution. On the have-nots' side, they include inadequacies of the poor community's socioeconomic infrastructure and knowledge-base, plus difficulties of organizing a representative and accountable citizens' group in the face of futility, alienation, and distrust $(1969,217)$.

This holds especially true for Aboriginal communities in Canada, where the paternalistic attitudes of governments towards Aboriginal groups have prevented Aboriginal peoples from being decision-makers of their own lives.

The second question asked pertains to the consultation mechanism employed, and which party decides upon the consultation mechanism that will be adopted. Establishing this is important because the mechanism chosen-and, specifically, how decisions will be decided upon-will determine the degree of influence participants will have on the outcomes. For example, examining Arnstein's typology (Figure 1), the rungs at the bottom 
of the ladder, therapy and manipulation, are considered to invoke "nonparticipation," enabling power holders to "educate" or "cure" participants." Such mechanisms that invoke nonparticipation can be found in consultations, such as open houses and focus groups. On the other hand, the top rungs, delegated power and citizen-control, empower have-not citizens with the majority of decision-making seats or full managerial control, such as citizen juries and ballots (Arnstein 1969, 217). The ability to choose which form of consultation to be adopted can allow participants a greater role in determining the final policy outcomes. Allowing all parties a say in the selection process also removes the ability of one party, usually the government, to retain a hegemonic position over the process.

This is crucial in the Aboriginal context, as governments and Aboriginal peoples have commonly encountered roadblocks during the negotiations process. As Van Den Burg states,

A substantial part of the problem with consultation is that the government has failed to devise an appropriate mechanism for consultations. A method of joint decisionmaking between Aboriginals and non-Aboriginals must be conducted. Few policymakers ... possess the field experience to understand their target population, making it difficult to design programs that properly address Aboriginals' needs $(2009,20)$.

In other words, evading consultation a priori consultation undermines the objectives of the consultation process because it demonstrates the government's unwillingness to share decision-making power from the start. As Atkinson and Willis state,

it is again important that the community has ownership over the process, that it is not something imposed from outside without consultation ... the direction of approaches by personnel from outside the community will undermine the longerterm effectiveness of approaches which are importantly about what communities determine for themselves as the key goals of capacity building $(2005,10)$.

Therefore, for public consultations to be fruitful, governments must negotiate the process with Aboriginal stakeholders prior to the actual consultation. Doing so demonstrates the government's readiness to consult in good faith, a minimum requirement for regaining the Aboriginal community's trust and redistributing power.

\section{Empowerment Component}

The empowerment component focuses on the democratic concerns of political inclusivity, mechanisms for enabling participation, and a clear communication process. At this point, evaluators need to determine: who was called to participate and how representatives of the group in question were chosen; whether the necessary tools for empowerment (participation) were made available to all participants; and if the communication process was open and respectful. This is an important component because power-shifting (the redistribution of power from power holders to stakeholders) is not only concerned with outcomes, as was the case with Arnstein's analysis. Rather, power-shifting can also occur, and is most important, on an internal level, where actions take place. 
Specifically, Hannah and Lewis (1982) argue Arnstein's analysis is one-dimensional in relation to citizen power. The authors argue that citizen power has a second dimension, which is the degree of citizen power over the internal decision-making process (membership, internal committee dynamics, committee goals, and objectives). The research conducted in this study agrees with Hannah and Lewis' argument, which is that power-shifting can occur both internally and externally. However, it is the internal decision-making process that determines the success of any public consultation structure, which is measured by the ability of participants to assume power, since both power-shifting and trust building is internal to the process.

In regards to the first set of questions on representation from the framework, the work of Turnball and Aucoin is important, as the authors state that one of the limitations of public consultation is that it offers "a role only to those citizens who volunteer to participate. Governments do not always actively recruit a diverse set of opinions" (2006, 1). Furthermore, Catt and Murphy state that the failure of governments to seek input from members of ethnic, national, and religious minorities will result in major obstacles in the domain of both legitimacy and efficacy $(2003,411)$. Due to these limitations, for effective participation to take place, the group in question should have adequate representation. This is especially true for policies affecting Aboriginal peoples, as their exclusion from the political process has been detrimental to both Aboriginal societies and the Canadian state.

To rectify this problem, Catt and Murphy $(2003,411)$ suggest that the important question to be asked here is: Who speaks for or represents the group, and how are these representatives chosen? Governments have several ways to go about this task, such as random sampling. Although this mechanism has its merits (e.g., it best approximates the principle of individual equality), Aboriginal decision makers do not have a choice in the matter. Catt and Murphy argue that allowing parties to pick their own representatives is most effective, and is especially important for historically disadvantaged or marginalized groups who may not trust the government to choose representatives who will honestly and effectively represent that group's interests. The authors put forward a better mechanism, in which governments provide for a process of group selection, "wherein particular government-designed groups or associations would choose their own representatives to speak on their behalf" (412).

In these cases, the group in question may decide to elect their representatives or to choose them through informal methods. Catt and Murphy argue that the importance and benefits of group selection are that it allows representatives to be directly accountable to the members they represent, and to ensure that those representatives provide an accurate account of the perspectives and priorities they represent $(2003,412)$. This is vital to the group whose interests are at stake, and to the government that requires as accurate an account as possible in order to achieve efficacy and legitimacy in the policy-making process. To this end, given the cultural sensitivity of Aboriginal policies, effective Aboriginal participation can occur if Aboriginal members can appoint/elect those whom they believe will best represent their interests at the consultation table. Furthermore, entrusting members to choose their 
own representatives demonstrates power-shifting on the part of government, leading to greater trust in the process and, thus, in government-a prerequisite for successful public consultation.

The second component of the evaluation framework being examined is concerned with identifying the availability of avenues/resources needed to allow effective participation to occur. Participation cannot be meaningful if the appropriate resources (Internet, transportation costs, access to information, sufficient time, etc.) and information pertaining to the issue are not made available to participants. As Turnball and Aucoin state, "The effort to make participants as informed as possible enhances the civic education aspect of the deliberation exercise. It also helps to 'level the playing field' between those participants who initially are knowledgeable about the issue and those who are not" $(2006,9)$. This is especially critical for Aboriginal-state relations, because governments possess the resources and information to become better informed more quickly, as compared to participants, who may lack the means to become as well informed as swiftly.

For example, Aboriginal participants experience several personal and political barriers that affect their ability to effectively participate, such as limited access to information and government representatives, lack of education, lack of employment, and lack of resources (i.e., transportation, daycare, lieu time). Without providing Aboriginal participants with the necessary and adequate resources, knowledgeable input cannot and will not occur, which will, in turn, result in government officials pushing their agenda onto Aboriginal participants (van den Berg 2009, 20) and retaining the power dynamic in their favour. Access to information can help remedy this and will allow for the possibility of equality in the process. As Catt argues, "the ability to take part in the democratic process is an important step in attaining equality. ... Even if all have the same access to the democratic procedures there are other conditions that need to be met, such as availability of information" (1999, 9). To this end, it is the government's responsibility to provide adequate resources as the party requesting an Aboriginal presence at the table.

One such resource, which is of particular interest to the research conducted here, is training for participation or leadership in public consultations: a component that King et al. highlight is missing elsewhere in the literature. Though information and resources may be made available to participants, without training specific to the requirements of the process, participants may not possess the capacity to effectively contribute. Atkinson and Willis (2005) argue that " $[\mathrm{t}]$ raining residents in generating their own research and recommendations not only helps communities to communicate to themselves the results of community building activities but also raises the skills base of members of the community trained in, for example, the use of surveys and their analysis" (11). For many Aboriginal peoples, this is the case. Owing to the group's damaged trust in the state, and the institutions that are part of the democratic process, Aboriginal leaders have found themselves politically isolated and excluded.

Fletcher, McKennitt, and Baydala (2008) take stock of the importance of training for participation in their own research. Though the authors are referring to community capacity 
building strategies (a form of public consultations), their observations as they relates to effective leadership are important for promoting participation. According to Fletcher et al. (2008), "Effective leadership promoting participatory decision-making may be the most important characteristic of a community's capacity to promote participation" (26). However, when there is an absence of community leadership to begin with, governments need to provide training to develop community leaders who can further the participatory agenda. Without this, public consultation structures fail or are unrepresentative of the community because the pool of participants remains small and static. This is especially true of Aboriginal communities.

As Taylor writes, "leadership has to be the focus of specific attention to any capacity building exercise by all (including communities themselves) and involves two main broad purposes: the enhancement of the capabilities of existing Indigenous leaders and the creation of a larger pool of Indigenous leaders available from within the community" (2003, 12). A government's willingness, or lack thereof, to invest in Aboriginal participants, and by default the process, indicates to some degree the readiness by governments to equalize the powerbase and consult in good faith. Such an environment encourages participants to make connections and develop relationships that allow for legitimate policy outcomes and the development of trust (King et al. 1998, 324), thereby bringing Aboriginal peoples closer to the policy-making process and the democratic process at large.

The last characteristic, and one of the most important on the path to empowerment, is an open and respectful communication practice, where communication is a two-way process in which members give and receive feedback to and from government. This is an important characteristic of successful public consultation because open lines of communication allow for public consultations to serve as a sounding board for preliminary ideas. If the communication process is stifled by government, so that ideas and concerns cannot be exchanged and policy decisions occur behind closed doors or in secrecy away from the ears of the committee, the possibility of power-shifting and trust-building becomes unattainable because governments will continue to assert their authority without being accountable to the committee and the community at large.

\section{Relationship-Building Component}

Component three, the relationship-building component, is twofold. It examines the extent of both external and internal political will for the process, and how final decisions are agreed upon. More specifically, it looks at how the findings, participants' input, and comments are incorporated into the final policy decisions. Returning to Arnstein's ladder, the middle three rungs offer participants no assurance that their input will be taken into account or used. Participation at these three levels is tokenistic in nature, with governments having the final say. In order to move away from tokenistic forms of consultation towards more effective consultation, Aboriginal peoples must have an equal opportunity to affect the final outcomes. Fulfilling the criteria set in the framework demonstrates that governments are actively building relationships with Aboriginal members based on trust 
and respect, and avoiding age-old roadblocks to participation. Building strong Aboriginalstate relationships can occur in the ways outlined below.

\section{Political Will}

Establishing the extent of the political will generated by actors external and internal to the process is an important component when dealing with government strategies that involve communities of peoples in which the success of the strategy is dependent upon community participation. As Hannah and Lewis state,

Citizen control may also be associated with the extent to which committees seek independent support for their recommendations. Although the literature is silent on this point, it seems reasonable to suspect that committees that exercise control and initiative in their external relationships will also engage in controlling behaviours in their internal proceedings. We therefore hypothesize a positive relationship between committees which seek independent support for their recommendations from individuals and groups in the community and committees which have a high degree of internal citizen control $(1982,44)$.

This component of the evaluation framework examines the notion of political will, but takes a closer look at the external (Elders, Aboriginal Community Organizations (ACOs), and employers) and internal actors (governments) who are important to the urban Aboriginal context. The importance of examining this element arises from the literature (Wherrett and Brown 1994; Loxley and Wien 2002; Newhouse 2002) on urban Aboriginal communities, which demonstrates that urban Aboriginal peoples possess the potential to form their communities in a non-rural, non-reserve setting through the governance of their organizational capacities. In other words, transforming their urban communities is not vested in self-government arrangements, as it is on reserves; rather, the transformation is embedded in the institutional capacity of urban Aboriginal organizations (Manitoba Metis Federation, Assembly of Manitoba Chiefs, Native Women's Transition Centre, e.g.), both locally and nationally.

The political power these organizations possess in charting a future for the urban Aboriginal community is unlike that possessed in other communities in Canada. Aboriginal peoples have been migrating to urban centres and creating communities for themselves for over eighty years, and have been politically vocal with their endeavours (Newhouse 2002, 243). The urban Aboriginal community has historical roots dating back to the 1960 s (244). The result has been strong leadership, which has put Aboriginal organizations at the forefront of the communities' governance structures and political representation. It has also led to an infrastructure where urban Aboriginals, according to Newhouse,

developed political institutions to advance their own interests in the city, in the form of Aboriginal councils of local Aboriginal organizations and formal advisory bodies to municipal councils. A cadre of individuals can act as learned and informed representatives of the Aboriginal community in various mainstream fora dealing with Aboriginal issues (e.g., Aboriginal Council of Winnipeg) (250). 
Particularly important are the collaboration and coordination of the organizations and the community, which have resulted in the current governing infrastructure. With this in mind, the important thing to evaluate at this point is how much political will and support is present to advance the UAS, and how much influence the committee has in influencing final impacts. The UAS needs to exhibit political support external to the committee, from those such as Elders, Aboriginal community organizations (ACOs), and employers, and internal to the committee via the presence of government at the table. The summation of these parts creates a synergy that enhances the participatory process, rendering it more effective.

Elders

Elders are important actors within the process because of the wisdom, knowledge, and guidance they possess. In particular, they represent Aboriginal culture and remind the community of who they are and where they come from. Federal government policy papers tend to ignore the cultural maintenance dimension when focusing on socio-economic development in cities, although that kind of development has been recognized by important documents such as the Royal Commission on Aboriginal Peoples (RCAP 1994). According to Graham and Peters, RCAP makes an important contribution to the linkage between cities and culture, and that " $[\mathrm{t}]$ he Commission found that maintaining Aboriginal cultures and identities was important to urban Aboriginal Peoples, but that they faced particular challenges associated with lack of access to people (especially elders), places (especially the land) and practices (especially ceremonies) important to cultural survival" $(2002,30)$. Furthermore, the authors argue, "it seems likely that support for Aboriginal cultures and initiatives that focus on the reduction of poverty need to occur at the same time" (31). Without a mechanism for incorporating culture into the process, Aboriginal participants may feel the process is government-dominated without an appreciation of their histories and culture. The presence of Elders at the table makes the process more culturally appropriate, and provides a link from the committee to the community.

ACOs

ACOs are central to the success of any public consultation, especially in an urban setting where Aboriginal governance is dependent on the institutional capacity of the ACOs. A discussion and/or analysis of ACOs is rarely absent from the literature on urban Aboriginal peoples and policies. As Newhouse states, "a huge network of institutions has emerged within the urban Aboriginal communities. Over the last four decades (1960-2000), urban Aboriginal landscapes have been transformed through the emergence of Aboriginal organizations designed to meet the many needs of a growing urban population" (2002, 244). At times, ACOs are the political representatives of the urban population, unlike a community that is circumscribed by a land base where leaders are clearly selected (Walker 2005, 398). Successful public consultation structures require ACO cooperation and support, politically and/or financially. 


\section{Employers}

Another element absent from the public consultation literature that is specific to the urban Aboriginal context is the role of employers. Since public consultation structures are heavily reliant on the manpower of the voluntary sector, as is the UAS, and given that many Aboriginal leaders and Aboriginal community activists are employed and/or direct Aboriginal organizations-both non-governmental organizations (NGOs) and not-forprofit organizations (NPOs) - it is only appropriate to assess the level of support committee members receive from their respective employers. Employer support affects a participant's ability to contribute by allowing the participant time and space to attend meetings, workshops, and community forums. Fletcher et al. highlighted barriers to participation in their own case study, and state that, "the practicalities of everyday responsibilities meant that ... attendance at research workshops and scientific presentations and meetings was often incompatible with everyday community responsibilities" $(2008,27)$. The ability to manage both participation on the UAS and work-related responsibilities is dependent, to some degree, upon the support committee members receive from their place of employment.

\section{Governments}

The UAS has partnerships with urban Aboriginal communities and all three levels of government. As is the case with any partnership, an endeavour will not be successful without all partners at the consultation table, sharing in the enterprise. Since the government, in theory, has final say regarding the UAS and its funding structure, governmental support, or lack thereof, will dictate the success or failure of the UAS, and affect the ability of Aboriginal community members to push policy initiatives forward.

\section{Decision-making Authority}

The literature on public consultations highlights that governments do not always commit to using public input in decision-making and, more importantly, consultations often occur late in the process. To build trust, Turnball and Aucoin suggest that,

It must be clear to participants in the deliberation process that their efforts are not simply for consultative purposes or to validate decisions that have already been taken ... if citizens are to be expected to sacrifice the considerable time and energy required by meaningful public deliberations, they must be assured that the result of their deliberations "matter." A deliberative procedure that fails in this regard will be interpreted as a shallow commitment to public involvement and may even undermine, rather than enhance, public trust in government $(2006,7)$.

Other scholars (Arnstein 1969; Catt and Murphy 2003) refer to this approach as "tokenism," or phony consultation. As Catt and Murphy (2003) put it,

... many view as tokenistic any process of consultation that does not give citizens control over decisions. A somewhat more cynical view is that consultation can be 
used by government to provide policy-makers with a veneer of legitimacy without actually incorporating into the policy any of the input it gathers $(2003,419)$.

That is, in order to move away from tokenistic forms of consultation towards more effective consultation, Aboriginal peoples must have an equal opportunity to affect the final outcomes, as Arnstein's typology would indicate.

Referring again to Figure 1, we see that there is little room on the bottom rungs for effective participation because control of the process remains firmly in the hands of government, while the top rungs provides participants with the opportunity to make real decisions. This knowledge is most important for Aboriginal leaders, as they endeavour to remove the reins of colonialism and work towards political inclusion for self-determination.

Democratic decision making as a means of obtaining self-governance to fulfill the ideal that no person should be decided for another is an important strand of argument in justifications for democracy ... The other strand to the argument of self-government is that all decisions should be made only after each person has had an opportunity to express their view. Only if the decision is made by all is it legitimate (Catt 1999, 8).

Decision-making power through the consultation process is a step towards political inclusion, and the development of trust between governments and Aboriginal peoples.

\section{Findings And Observations}

This section analyses the three components of the evaluation framework as they apply to the Winnipeg UAS case study. Table 3 summarizes the presence or absence of each of the criteria in the Winnipeg case. This section continues with an analysis of the levels of achievement for each criterion in Winnipeg to determine the extent to which the UAS consultation process meets Arnstein's standards for effective citizen participation. The findings conclude that the decision-making process for the Winnipeg UAS does, in fact, meet Arnstein's standards, and that the presence of all three components is largely evident.

TABLE 3: Winnipeg Findings

Components

Developmental

Empowerment

Relationship Building

\section{Criteria}

a) Deciding consultation mechanism

b) Deciding subject matter

a) Deciding representatives

b) Availability of resources and training

c) Communication process
Winnipeg

Yes

Yes

Partial

No

Evident
a) Political will
b) Use of input
Yes
Yes 


\section{Developmental Component}

\section{Deciding Consultation Mechanism}

Allowing Aboriginal participants to determine the consultation mechanism is an important component for developing trust and establishing the degree of authority members will have in affecting final outcomes, and this element was present in the Winnipeg case. The UAS, prior to its implementation, was a pilot program with Winnipeg being its testing grounds. Before the implementation of the UAS in Winnipeg, the Government of Manitoba used the Manitoba Round Table on Environment \& Economy as a platform to conduct public consultations for an Urban Aboriginal Strategy.

The Manitoba Round Table's Urban Aboriginal Strategy Subcommittee, composed of community representatives invited by the provincial government, was formed to develop the public consultation process for the UAS. The work of the subcommittee focused on "ensuring the relevance and effectiveness of the Urban Aboriginal Strategy public consultation process and strategy development, and develop a public consultation process work plan" (Government of Manitoba 1998, 9). The subcommittee's work established six community workshops in the following policy areas: the environment, economy, healthy communities, partnerships, priorities for action, and an action plan workshop (Government of Manitoba 1998, 9). The workshops were well-attended, with over a thousand participants.

The three main purposes of this consultative process were: to strengthen communication and consultation processes; to develop respect, mutual trust and understanding between Aboriginal peoples in Winnipeg and the three levels of governments; and to influence policy development and result in action through policy implementation (Government of Manitoba 1998, 7). The important element to draw attention to is that the Government of Manitoba introduced the UAS to the community a priori implementation. That is, the UAS was not forced upon the community. Rather, it was developed in partnership with the community prior to its implementation. This demonstrated the government's respect for Aboriginal input and signified some degree of power-shifting, in which the community had some ownership over the process.

Prior to the implementation of the UAS, the consultation process also resulted in the decision to employ a consensus model of decision-making. The sub-committee of the Round Table decided on the model after consultation with the community at large. Consensus, in this instance, was not based on a unanimous opinion by all members; rather, the model strives to arrive at unity of opinions (CGC Orientation Manual 2010, 4.12.3). A consensus model is intended to create an environment conducive to respecting the diversity of opinion and encourage debate, in which discussion amongst the group continues until a unity of opinion is reached. There are two relevant items: one, the decision to employ a decision-making consensus model was decided by the community before implementation, and not the government; and two, by employing this model, the Steering Committee possessed a mechanism for decision-making authority. Allowing the 
Aboriginal community the opportunity to choose the method for arriving at decisions displays willingness by governments to entrust the community with decision-making authority related to the process. Granting the community this responsibility also suggests that the government understands the degree of authority it is delegating to the community, and will accept this process as common practice.

Even more importantly, the willingness on the part of government to agree to a consensus model places the UAS consultation process on the higher rungs of Arnstein's ladder, and on the partnership rung, specifically, in which participants and governments "agree to share the planning and decision-making responsibilities through such structures as joint policy boards, planning committees and mechanisms for resolving impasses" (Arnstein, 222). The effects of this decision was observed in the individual interviews, where many members noted that there was not much bureaucratic control by the government, resulting in a mutually respectful and overall good working relationship with the government representatives at the table. As one Aboriginal member said,

It is not a heavy-handed process where government is leading everything, it is a good process. When it comes down to final say, we have consensus. If it is a big issue, they (government) will pull rank. The province has only done it once because they needed the money for something else. The province reported that to us and they came and explained their reasoning. Afterwards I could understand why they did (personal interview with UAS committee member, 2 May 2012).

In the fifteen-year history of the UAS in Winnipeg, the government has only asserted their complete political authority twice, and both incidences dealt with project selection and not the process.

\section{Deciding Subject Matter}

The subject matter to be discussed at a meeting is decided by the committee as a whole. All processes, such as the committee's terms of reference, members' selection process, Strategic/Community Plan, and project selection, are decided and developed wholly by the committee based on feedback received from the larger urban Aboriginal community during the community consultation process. For instance, the committee members decide the policy direction of the Strategic Plan, which is updated every two or three years. The development of the Strategic Plan is based on direct consultation with the Aboriginal community in Winnipeg, where the Steering Committee holds annual community forums with Aboriginal organizations and community members to gather feedback. The feedback is then used to shape the direction of the Strategic Plan. Bringing these aspects of the process back to the Aboriginal community is a demonstration of the government's willingness to redistribute power, and to empower Aboriginal participants in setting the policy agenda. This changes the power dynamics of Aboriginal-state consultations by operating outside of the status quo, which, according to Arnstein, is essential for creating an environment conducive to effective participation. 
The UAS process is heading in the right direction towards a renewed Aboriginal-state relationship. By consulting with the community a priori implementation and delegating many aspects of the design, management, and delivery of the process to the Aboriginal community, OFI is building trust and capacity with the committee and the community at large. This is the first step towards ensuring effective participation can and will take place. The respondents felt, specifically at this point, that all three levels of government had made a genuine effort to form a partnership with the committee based on cooperation and mutual respect. Transferring the responsibility of strategy design from the government to the community gave the Aboriginal community the opportunity to understand the importance of the Strategy Plan and to feel part of the process, thereby giving the community a stake in the success of the UAS. At this point, the participants are somewhat invested in the Strategy and less likely to feel that their participation is meaningless.

\section{Empowerment Component}

This component contributes three elements to the evaluation process: representative selection, availability of resource and training, and the presence of an open and respectful communication process. When present, each element equips or empowers participants with the resources necessary to participate effectively in the decision-making process. Given the socio-economic and political marginalization of Aboriginal peoples, it is not surprising that there are numerous personal barriers (education, income, time, etc.) that would prevent some from participating. For these reasons, it is the responsibility of the government, both within their fiduciary and constitutional duty, to provide Aboriginal peoples with at least the minimum resources needed to participate effectively, especially if and when government is the party initiating consultation. If this does not occur, Aboriginal-state consultations are destined to remain on the first two rungs of Arnstein's ladder, and the failure of any public consultation mechanism is assured. Each of the three components is analyzed below.

\section{Representation}

For effective participation to occur, the group engaged in consultation must be able to select representatives and chose the method of selection. Winnipeg's model of representation best approximates group selection, the ideal selection method advocated by Catt and Murphy. Community representatives on the steering committee are selected in a process handled by a selection committee, which is made up of representatives from the three levels of government: two representatives from political organizations (the Assembly of Manitoba Chiefs and the Aboriginal Council of Winnipeg), two elders (CGC 2010), and two positions to be filled by nomination. An independent consultant is brought in to ensure the selection process was as unbiased as possible. This process is illustrated in the final report conducted by Celeste McKay Consulting in 2012, entitled, the Final Report Community/Government Committee (CGC), conducted by Celeste McKay Consulting in 2010. The report stated that, " $[\mathrm{w}]$ hile the other political organizations were invited to participate on the Selection Committee, they did not put forth a representative to sit on the committee. A Metis Elder 
and an Inuit Elder were invited to participate but were not able to attend" $(2010,1)$. One member noted that some organizations did not want to participate because they believed the UAS agenda conflicted with their own organization's agenda (personal interview with UAS committee member, 2 May 2012). However, despite the lack of participation by Aboriginal representatives, this statement demonstrates the government's commitment to having representation inclusive of the Aboriginal community. Unfortunately, only two nominations were received for the two nomination seats, and these individuals sat on the selection committee. Having more nominees would have been preferable to show interest in the process and to have the option to draw from a wider pool of talents.

The original Selection Committee created the selection criteria to guide the process. In addition to the original "call for nominations" for the Selection Committee, a similar "call for nominations" for Steering Committee members was widely distributed through Aboriginal organizations and networks via emails. As the Final Report (2010) states,

A call for participation was sent out for both participation in the Selection Committee of the CGC as well as the CGC itself by email on or about January 28, 2010 to a number of individuals and organizations from a list of service providers and community organizations (provided by OFI-MB) as well as to the following list-serves: the iuscommunitylink list serve, the University of Manitoba's Professor Fred Shore's list, Volunteer MB's list serve and the Red River Community College's list serve. It was also published on the online version of the Drum. The Metro and other news publishing possibilities were not practical given the time frame for submission of applications (1).

Applicants were asked to fill out the UAS Application Form and submit a recent resume. Most members stated they found that the "call for nominations" was widely distributed and effective. A total of twenty-seven nominations were received to fill ten seats on the Steering Committee.

Another representation concern existed with the first set of committee members under the WPA. Originally, when the UAS was part of the WPA, representation was based on representation by organization. This created conflicts amongst members, dividing those who felt their sector/organization was not being represented in terms of funding allocation and those more senior members who were able to push and receive funding for their specific organization (personal interview with former UAS committee member, 25 April 25 2012). Most members noted that the conflicts arising from the first set of Steering Committee members surfaced because members were acting as representatives of their organizational affiliations, aware there was government funding to be allocated. However, representation based on organizational affiliation is no longer practiced.

When the WPA completed its mandate on 31 December 2009, the UAS became part of the Aboriginal Strategic Planning Circle (ASPC) and began playing a larger role in setting the rules and agenda of the Winnipeg's Strategic Plan. In its new incarnation, a new set of members was chosen for the Steering Committee now under the auspices of the ASPC. To avoid conflict, representation moved from being organizationally based to individually 
based. The majority of the members interviewed noted this was more effective, because the representatives no longer carry their organizational agenda/mandate with them. One member noted that the change in selection criteria meant there was no agenda pushing, and hence little conflict of interest (personal interview with UAS committee member, 17 April 2012). Since the renewal of the UAS's funding in 2010, mechanisms have been established to avoid further conflicts of interest established in the "Terms of Reference." For example, if a member's affiliated organization is on the table for discussion/debate or has submitted a proposal for funding, the member must recuse themselves when committee voting occurs (personal interview with UAS committee member, 17 April 2012). Such mechanisms appear to be working for the committee and this has been noticed by most members.

This is not to argue that mechanisms for choosing representatives are not without their flaws. The limited scope of the "call for nominations," for example, in which a privileged few Aboriginal community members were called upon, meant governments were not forced to provide additional resources in terms of training members on how to manage a Steering Committee and how to effectively engage with the community. Instead of training others to become possible Aboriginal leaders in their community, governments are limiting the quantity and quality of participation by approaching more dominant and politically vocal representatives who belong to well-established Aboriginal organizations.

For Aboriginal communities, the need to build consensus and trust, and to empower as many members as possible should be a priority for governments when renewing the Aboriginal-state apparatus. Without these elements, the same few, privileged members will continue to come to the table to participate and provide governments with a narrow, and often times biased, viewpoint of what they believe community needs are. As James Glass states,

Selection of advisory committee members often depends upon locating individuals who are interested and who are willing to serve, and, although a random list of potential members might be generated, the probability that each would be willing to serve would be extremely small. Selection of members, then, is a non-random process that is not likely to produce a statistically representative sample $(1979,186)$.

One former member alluded to this point when they said,

There was money on the table and it seemed it was going to well-connected organizations and that's where the money was going. There were not enough degrees of separation between who was giving the money (Steering Committee members) and was getting the money (their organizations)... at that time it was strong-armed. The five alphas would decide how decisions were to be made and what decisions to be made (personal interview with former member, 25 April 2012).

In other words, without expanding the scope of representation, the purpose of community representation within this consultation model becomes a pointless exercise, one in which a dominant few control the process and outcomes in the name of the community but without genuine community input related to issues of representation. A more representative process 
can be realized when governments understand that they need to be the main provider for resources and training, the foundations upon which to build community capacity, and so ensure effective Aboriginal participation in consultation both now, and in the future.

\section{Resources and Training}

This component includes those tools, resources, and training required to allow for effective participation to occur. This may include time (deadlines, personal time), resources (funding), and access to information (for incoming members, for referencing projects, for service-delivery, etc.). Training can include skills training on chairmanship, how to build consensus, how to work around gridlock, leadership skills, and so on. Training can also include much larger management mechanisms, such as community capacity building, Aboriginal-state relationship building, mechanisms for dealing with different sectors (non-profit, voluntary, private), and rules of engagement. However, going further into these elements delves deeper into the questions of Aboriginal-state governance, and is beyond the scope of this paper. For the purposes of this analysis, the first set of criteria will suffice.

When members were asked the following question, "Were the tools/resources needed for participation made available to you?" (Appendix 1), the general consensus was that adequate time and funding was lacking. In terms of time, most interviewees responded that the federal government asked for too much information in too short a period of time, and deadlines to access funding placed too much pressure on individuals to start their projects. In addition, one member commented that the rigid and formal administrative processes required by the government makes it difficult to get things done, such as moving forward to the planning aspect, and especially when the process is volunteer-based (personal interview with committee member, 1 May 2012).

The roadblocks within the administrative process include things such as record keeping and consensus-building. For example, record keeping requires setting the agenda and approving the minutes of the meeting. The consensus-building model requires every member to agree on the minutes, which can be time consuming. As one member noted,

Things tend to drag on sometimes, like we will talk about how to format our agenda for like thirty minutes when it can be done in less than one minute ... We need to have more of a community focus than a focus on the process. There's a tendency to overdo things like talking about agenda items and the decision-making process. It's not operating as efficiently as it could be." (phone interview with community member, 14 January 2012).

Most members expressed similar sentiments, stating that the consensus model is too inefficient, especially when the efforts are volunteer-based and require all members to commit to one full day a month. Since funding needs to be allocated before the end of the fiscal year, members find it challenging to allocate funding while adhering to the administrative process. Members stated that such processes prevented the committee from focusing on the real needs of the community, such as services and program needs. 
The challenges presented here highlight the difficulties members face as representatives of their community and as government partners, and affect the committee's ability to assess the needs of the community properly, and to identify service gaps. In other words, their ability to effectively participate is compromised when, within the limited time frame they possess, too much of a focus is paid to the administrative process.

During the interview process, all members stated that funding is inadequate to redress the concerns related to urban Aboriginal poverty such as housing, addiction, and unemployment. However, governments view UAS funding as "seed money" to mobilize the community to align organizational efforts and cooperate. As one government representative stated, "We can do research and play an advocacy role to help support housing, we cannot actually provide housing. All community elements are there to provide this, we just help mobilize it. This is the type of engagement that leads to opportunity building" (personal interview with government representative, 2 June 2011). The governments in Winnipeg believe they are there to facilitate and mobilize the knowledge of its committee members to further the Strategy. Based on these differing views, there is clearly a disconnect between the government's expectations of the Strategy, and the committee's understanding of UAS funding.

On this note, most members commented that the limited funding made it difficult for the members to play a significant role in the community, though all members expressed the desire to. As one member noted, "We're just a government body with a small pot of money to play with, only $\$ 1$ million per year ... the UAS is not building capacity. Capacity is when you make organizations or individuals stronger and more able to look after themselves and participate on their own" (personal interview with UAS community member, 2 May 2012). This statement speaks to how the committee views itself in contrast to how the government regards the committee. As another member stated, "Traditionally this has been a funding committee. I feel we have the opportunity to do a lot more. I am here to make a difference, not just to give out money. It is just project funding. It is not long term, you cannot guarantee it for the next year and you expect projects to go out and get additional funding and that is unfortunate" (personal interview with community member, 18 April 2012).

In terms of their ability to access information, all members noted that information on the Winnipeg UAS was sufficient in regards to the availability of background information, overcoming the learning curve for new members, historical information, and any information needed from the government, such as reasons for refusing project funding. In addition, all minutes from previous meetings are appropriately archived and accessible if needed. Adequate record keeping makes it easier for new members to understand what is taking place in terms of ongoing projects, the process and the procedures of the UAS, and the history of the UAS. This allows incoming members the opportunity to quickly become informed and to participate. Several members noted that there was a learning curve upon joining the committee. However, it was easily overcome because all necessary documents were available and organized (personal interview with committee members, 30 April 2012). The only critical barrier to accessing information according to many of the members was the lack of information on project outcomes and results. 
Several members commented upon the need for evaluation reports to assess how the funding is being allocated and what, if any progress is occurring within the community; in other words, accountability for how the money is being used, which would assist in determining future funding strategies and allow for more effective and knowledgeable UAS participation. This was a concern expressed by Aboriginal members and government representatives alike. As one government representative stated, "There needs to be more of an ongoing evaluation process. Not to critique the projects but ensuring our overall goals are met. We take steps to address urban Aboriginal poverty but we don't know if they are working" (personal interview with government representative, 30 April 2012). In this case, the need to have real and constructive knowledge of project funding is an essential component of effective participation. Without knowing what is successful and what is not, governments and Aboriginal Committee members cannot effectively build community capacity.

However, providing adequate resources, training, funding, and information is a daunting task for governments and a roadblock to effective participation for members. For one, adequate reporting (record keeping, program evaluations, etc.) requires time and manpower, something volunteers cannot fully offer and/or possess. On the other hand, without these elements, participants cannot effectively provide valuable input, especially if the committee experiences high turnover. Governments must find a way to reconcile their administrative process with the needs of the participants. Specifically, it is the onus of the government, whether by providing the administrative capacities or reducing administrative requirements, to maximize the efforts and time volunteers dedicate to the UAS. This is not a simple task for governments, as they must continue to be accountable to taxpayers when public funds are dedicated to one segment of the population. When it comes to public consultations, governments need to find ways to balance the needs of one particular group with the democratic demands for accountability and transparency of society as a whole.

\section{Communication Process}

The other, and perhaps one of the most important, aspects of any consultation process are the lines of open and respectful communication, meaning communication leading to accountability for the actions of each member, whether they are a member of the government or the community. If and when this occurs, government appears increasingly legitimate in the eyes of the Aboriginal community, which may act as an incentive for greater future democratic participation by Aboriginal peoples. However, Aboriginal peoples tend to distrust the political process, and for good historical reason. One of the important lessons learned from Winnipeg is that communication between all parties is crucial to breaking down these barriers to participation. Without it, members will continue to feel as though the process is government-dominated and their participation meaningless, as has been the case in the past.

As one member stated earlier, the UAS is, "not a heavy-handed process where government is leading. It is a good process. If it is a big issue, the government will pull rank 
but this has only occurred once where the Government of Manitoba pulled rank but clearly explained why this was done and the reasoning made sense" (personal interview with UAS committee member, 2 May 2012. Emphasis added). On this point, all members stated that the process offers an environment conducive to open and respectful communication. Given that decisions are based on consensus building, without this genuine participation cannot take place and essentially would render the process of decision-making futile.

\section{Relationship-Building Component}

This component examines the presence of political will and support within the community for the UAS. The importance of political will and support in an urban context is, as the literature demonstrates, that urban Aboriginal peoples possess the potential to form their communities in a non-rural, non-reserve setting through the governance of their organizational capacities (Walker 2005; Newhouse 2002; Loxley and Wien 2002). Particularly important for the UAS is the collaboration and coordination of community organizations, and their willingness to partner with the UAS to achieve common goals. With this in mind, the important element to evaluate at this point is how much political will and support is evident to advance the UAS, and with that, how much influence does the committee have in influencing final policy outcomes? In theory, the UAS is situated on the higher rungs of Arnstein's typology. But, to reach that position requires the presences of several factors. For the UAS, it requires the presence of political support external to the committee, such as Elders, ACOs, employers, and internal to the committee, via the presence of government at the consultation table. The summation of these parts creates a synergy that enhances the participatory process, rendering it more effective.

\section{Elders}

The Steering Committee employs two Elders to attend monthly UAS meetings, who are prominent figures in the Winnipeg Aboriginal community. The Elders are akin to the parental figure in a family, providing guidance, mediation, and momentum when it has become lost as a result of the administrative process, and playing a key role in supporting the Steering Committee. As one member noted, "I think having the Elder there is very helpful, he's there to guide those conversations. He is always there to remind us why we are here and to respect our members. It provides insight and values of the Aboriginal community and reminds us to keep these in the forefront" (personal interview with committee member, 24 April 2012). The presence of Elders at the table adds a cultural component to the process that represents a degree of respect afforded to participants, and so increases the morale of participants and their ability to participate.

\section{Aboriginal Community Organizations}

Winnipeg has a long and deep history of Aboriginal organizations that have become political forces in their own right. Unique to Winnipeg is the collaboration and coordination 
these organizations have exhibited, working together with the community and for the community. Many of the organizations have united around common goals and visions for the community, such as CLOUT (Community Led Organizations Uniting Together), which is made up of nine organizations that are mostly Aboriginal-based. CLOUT provides services to the community and works as part of the community, rather than working in isolation from it. The importance of this feature in relation to the UAS is to show that when there is cooperation, there is less competition for funding from various organizations. Instead, funding can be provided to one established organization that provides services falling within the UAS mandate. Doing so results in less competition and dispersion of funds when there is a shared philosophy around the ways to build capacity within the community.

As one member states, "Winnipeg Aboriginal organizations work well together because they have shared values and beliefs within the management of organizations and delivery of services. Winnipeg has the highest density of Aboriginal people per capita and numbers gives us the capacity to develop innovative approaches to delivering services" (personal interview with community member, 1 May 2012). The ability to mobilize and unite around particular socio-economic policy areas has made the Aboriginal community in Winnipeg pioneers, creating initiatives such as the CCI (Comprehensive Community Initiative), which the UAS helped launch, that are not present in other parts of the country. Its main objective was to address addictions in the urban Aboriginal population.

Initiatives like this demonstrate the innovation that can be crafted when organizations possess the political will and determination to heal the Aboriginal community. The UAS is part and parcel of this initiative, and would not be able to make a difference in the community without the political support of the organizational infrastructure evident within the community. Much of the momentum to cooperate stems from the fact that many of the organizations in Winnipeg are Status-blind, and abide by common cultural beliefs and values. This fact lessens the possibility of conflict via "turf-wars" over a shared funding pot, allowing organizations to focus on the bigger picture. This is not to suggest that conflict does not exist within Winnipeg's urban Aboriginal community. However, the UAS has been able to overcome community conflicts based on some trial and error. For example, a "Conflict of Interest Guideline," established in the "Terms of Reference," prevents representation by organizations. These mechanisms ensure that conflict based on organizational representation is not present at the consultation table or, at the very least, can be overcome within the UAS decision-making process.

\section{Employers}

Another element of political support that is generally ignored in the literature, and which speaks to the external support provided from the community as a whole, is that of the employers. Many of the employers in Winnipeg that are Aboriginal organizations, and those people in government, understand the importance of the UAS for the community as a whole. The organizations support the UAS by allowing the individual members to leave 
their place of employment one day a month to attend the meetings and give additional time off, if needed, to participate in community events. All members, including government representatives, indicated the positive support they received from their employers to be part of the UAS. As one government representative said, "I feel I am supported by my managers and the mandate of our department certainly complements what the Aboriginal Strategy is trying to achieve. I get the political backing and bring that to the table" (personal interview with government representative, 23 April 2012). By nature, the UAS is a huge time commitment, consisting of at least one full day a month of contribution from fifteen members who are paid by their respective organizations. Employer support means the members are able to participate without fear of being reprimanded by their home organization.

\section{Government}

One of the critical foundations of building a renewed relationship based on mutual trust and respect is to have government political support evident at the table. However, presence alone does not guarantee success. In other words, political support through accommodation, understanding, and communication must be demonstrated during the consultation process. In Winnipeg, the political will demonstrated by all three levels of government is evident and strong. When asked what aspect could be attributed to the success of the UAS, all interviewees mentioned meaningful government participation as the main cause.

Use of Input

During the interview process, many of the community members asserted that the critical element to making the UAS work in Winnipeg was the support and feedback the committee received from the government. In addition, members felt that government representatives listened to and respected each and every members' opinion. This was because government representatives did not come to the table as public administrators; rather, they came as community members vested in the success of the Strategy. As one member stated, "We have really good government partners. We haven't had one government representative that has come just as a bureaucrat" (personal interview with committee member, 18 April 2012). Another member, speaking to the success of the UAS, noted that "we have a really good working relationship with government representatives. Government representatives are really sincere with wanting to have a working relationship and respectful partnership" (personal interview with committee member, 30 August 2011).

Even though the federal government can ultimately assert its authority, its willingness to listen genuinely and to respect the opinions of committee members overshadows the authoritative power it still yields. It is the reconciliation between these two elements that makes Aboriginal participants feel that their input is valued, and their participation necessary. As one member said, 
The people at the table are able to have a respectful discussion. I feel comfortable enough to state my opinion even if I disagree ... It is not all or nothing when it comes down to it and the government is very organized and they provide a lot of support and feedback ... If government is respecting the direction we are giving then it works even though the federal government has final say" (personal interview with committee member, 24 April 2012).

The Aboriginal-state relationship that is developing through the UAS process is creating an environment that is conducive to encouraging participation. Moreover, when members can openly and freely state their opinions without fear of ridicule by power holders, members can participate more effectively. As Arnstein argued, "effective citizen participation occurs when the have-nots can induce significant social reform which enables them to share in the benefits of the affluent society through mechanism of citizen participation which enables the redistribution of power" (216). Nowhere does this hold more true that in the Canadian Aboriginal context.

\section{Conclusion}

Winnipeg poses a unique case study because of its socio-demographic and political infrastructure. The city has the highest percentage (approximately 10\%) of Aboriginal peoples as compared to the city's overall population, and has one of the oldest Aboriginal voluntary sectors in the country. Because of these conditions, Aboriginal participation in the political decision-making processes are robust and noteworthy. This paper has established a framework for evaluating the consultation process that speaks to the Winnipeg dynamic. The framework determines several critical criteria that need to be present for effective participation to occur. Based on the case study examined here, for the most part, governments are providing the foundations for effective participation and so are building a relationship with the community based on trust and respect. Specifically, the government is incorporating mechanisms to equalize the power base by participating in $a$ priori consultation with the community, enabling the community to decide consultation methods and to choose representatives, providing participants with the resources and information required to enable knowledgeable input (albeit limited), ensuring open and respectful communication, and accommodating the cultural dimension of Aboriginalstate consultations (such as including Elders in meetings).

This is not to suggest that the UAS as a consultation process does not experience roadblocks. For example, the mechanism for choosing representatives continues to exclude many potential Aboriginal participants from the democratic process. Specifically, the lack of training for ensuring effective participation by community members continues to be an obstacle to building strong relationships with a wider sample of the urban Aboriginal community. As currently practiced, those strong figures within the Winnipeg urban Aboriginal community continue to be the ones called to the table when governments want to consult, and so this situation continues to be a barrier to inclusive participation. Other aspects required for effective participation to occur, such as political support 
from Aboriginal organizations and respective employers, come from the community as a whole. This suggests that even when the intent is there and executed, some aspects to equalizing power relations are outside the purview of government. This is especially true in the Aboriginal context, where community bonds make up the nucleus of the group. In these instances, governments must go beyond the scope of simply consulting by identifying ways to build community capacity that will serve the community, and future consultation programs in the long run. In the meantime, the UAS in Winnipeg exhibits characteristics which are critical to enabling effective participation of Aboriginal members. These characteristics are the foundation for building relationships based on trust and mutual respect and thus, removing roadblocks to democratic participation. This is vital to the political policy-making process because it demonstrates that genuinely democratic decision-making involving Aboriginal peoples and the state is possible. 


\section{Appendix I: Questions To Participants}

Questions related to participation:

1. How were you chosen or approached to be part of the Steering Committee (SC)?

2. What is your involvement in the SC?

3. Do you know how members were contacted and chosen to join the SC?

4. To your knowledge were members of the Steering Committee given the opportunity to decide the purpose or form of the consultation? Or, was this decided a priori your involvement?

5. What about consultation mechanisms, who gets to decide this?

6. Were the tools/resources (internet, transportation cost, access to info, sufficient time, funding, etc.) needed for participation made available to you?

7. What obstacles (trust issues, bureaucratic control, etc.), if any, do you think hindered your ability to fully participate?

8. Finally, in your opinion, what is needed to make the participation of members more effective?

\section{Questions related to the process:}

1. How was agenda/policy direction decided? In other words, what policy projects get pushed through and how/why?

2. How does the SC reach final decisions?

3. Is the process democratic?

4. How is your input used in the final decisions

5. How does the SC overcome conflict?

6. Is there any suggests on how to make the process work better for Aboriginal peoples?

\section{Questions related to the strategy:}

1. How is the UAS addressing urban aboriginal poverty?

2. Is it working? 
3. Is the UAS trying to be the face of the urban Aboriginal population in Winnipeg?

4. How does it attempt to forge relationships with the community and how does it build capacity?

5. Why do urban Aboriginal organizations seem to cooperate so well with each other?

6. Is the UAS an effective way for governments to work collaboratively with the Aboriginal community?

7. Would you be able to comment on why Winnipeg is one of the more successful UAS communities?

8. What elements were present that allowed Winnipeg to be a success?

9. Finally, what could make this strategy more effective for Aboriginal peoples in terms of the achieving the main goals of the UAS? 


\section{Appendix 2: List of Interviews-Winnipeg}

Community member. 30 August 2011. Phone interview conducted in Winnipeg. Community member. 13 October 2011. Phone interview conducted in Winnipeg. Community member. 14 January 2012. Phone interview conducted in Winnipeg. Community member. 17 April 2012. Personal interview conducted in Winnipeg. Community member. 18 April 2012. Personal interview conducted in Winnipeg. Community member. 23 April 2012. Personal interview conducted in Winnipeg. Community member. 24 April 2012. Personal interview conducted in Winnipeg. Community member. 1 May 2012. Personal interview conducted in Winnipeg. Community member. 2 May 2012. Personal interview conducted in Winnipeg. Former committee member. 25 April 2012. Personal interview conducted in Winnipeg.

Former government representative. 2 June 2011. Personal interview conducted in Winnipeg.

Government representative. 23 April 2012. Personal interview conducted in Winnipeg

Government representatives. 30 April 2012. Personal interviews conducted in Winnipeg.

Government representatives. 3 May 2012. Personal Interview conducted in Winnipeg. 


\section{Bibliography}

Aboriginal Affairs and Northern Development Canada. 2011. "Urban Aboriginal Strategy Projects (2009-2010 Fiscal Year)." Ottawa: AANDC. http://www.aadncaandc.gc.ca/ eng/1316007831303\#chp9.

Atkinson, R. and P. Willis. 2005. "Community Capacity Building-A Practical Guide." Paper No. 6: Housing and Community Unit. Hobart: University of Tasmania.

Arnstein, S. B. 1969. "A Ladder of Citizen Participation." Journal of the American Planning Association 34 (4): 216-24. http://dx.doi.org/10.1080/01944366908977225.

Catt, H. 1999. Democracy in Practice. New York: Routledge.

Catt, H., and M. Murphy. 2003. "What Voice for the People? Categorising Methods of Public Consultation." Australian Journal of Political Science 38 (3): 407-21. http:// dx.doi.org/10.1080/1036114032000133967.

Celeste McKay Consulting. 2010. "Final Report Community/Government Committee (CGC)." Winnipeg: OFI.

Clatworthy, S., J. Hall, and N. Loughren. 1994. "Urban Aboriginal Organizations: Edmonton, Toronto, and Winnipeg." In Aboriginal Self-Government in Urban Areas: Proceedings of a Workshop May 25 and 26, ed. E. J. Peters, 25-83. Kingston: Institute of Intergovernmental Relations, Queen's University.

Community Government Committee (CGC) Orientation Manual. 2010. Prepared by the Office of the Federal Interlocutor for the Winnipeg Urban Aboriginal Strategy Steering Committee.

Fletcher, F., D. McKennitt, and L. Baydala. 2008. "Community Capacity Building: An Aboriginal Exploratory Case Study." Pimatisiwin: A Journal of Aboriginal Indigenous Community Health 5 (2). Accessed March 2014. http://www.pimatisiwin.com/ online/?page_id=308.

Glass, J. 1979. "Citizen Participation in Planning: The Relationship Between Objectives and Techniques." Journal of American Planning Association 45 (2): 180-89. http:// dx.doi.org/10.1080/01944367908976956.

Government of Manitoba. 1998. "Towards a Strategy for Aboriginal Peoples Living in Winnipeg-Final Report, Conclusions, Findings, and Recommendations of the Manitoba Roundtable on Environment and Economy Urban Aboriginal Strategy Public Consultation Process." Winnipeg: Manitoba Round Table on Environment \& Economy.

Graham, A. and E. Peters. 2002. "Aboriginal Communities and Urban Sustainability." Ottawa: Canadian Policy Research Networks. http://www.urbancentre.utoronto.ca/ pdfs/elibrary/CPRNUrbanAboriginal.pdf.

Hannah, S., and H. Lewis. 1982. "Internal Citizen Control of Locally Initiated Citizen Advisory Committees: A Case Study." Journal of Voluntary Action Research 11.4: 39-52. http://dx.doi.org/10.1177/089976408201100405. 
Hanselmann, C. 2002. "Ensuring the Urban Dream: Shared Responsibility and Effective Urban Aboriginal Voices." In Not Strangers in These Parts-Urban Aboriginal Peoples, ed. D. Newhouse and E. J. Peters, 167-78. Ottawa: Policy Research Initiative.

Hill Sloan Associates Inc., Economic Consultants. 2008. "First Nation Consultation Framework." Project Report to the National Centre for First Nations Governance. Accessed 10 March 2014. http://fngovernance.org/resources_docs/First_Nation_ ConsultationFramework.pdf.

Loxley, J. and F. Wien. 2002. "Urban Aboriginal Economic Development." In Not Strangers in These Parts-Urban Aboriginal Peoples, ed. D. Newhouse and E. J. Peters, 217-42. Ottawa: Policy Research Initiative.

King, C. S., K. M. Feltey, and B. O’Neill Susel. 1998. “The Question of Participation: Toward Authentic Public Participation in Public Administration.” Public Administration Review 58.4: 317-26. http://dx.doi.org/10.2307/977561.

Maaka, R., and A. Fleras. 2000. "Engaging in Indigeneity: Tino Rangatiratanga in Aoteraroa." In Political Theory and the Rights of Indigenous People, ed. D. Ivison, P. Patton and W. Sanders, 89-112. Port Melbourne: Cambridge University Press.

Metro Vancouver Urban Aboriginal Strategy. 2010. Metro Vancouver Urban Aboriginal Strategy. City of Vancouver: MVUAS.

Newhouse, D. 2002. "The Invisible Infrastructure: Urban Aboriginal Institutions and Organizations." In Not Strangers in These Parts-Urban Aboriginal Peoples, ed. D. Newhouse and E. J. Peters, 243-54. Ottawa: Policy Research Initiative.

Newhouse, D., and E. J. Peters, ed. 2002. Not Strangers in These Parts-Urban Aboriginal Peoples. Ottawa: Policy Research Initiative.

Office of the Federal Interlocutor (OFI). 2010. "Community Government Committee Orientation Manual." Community-Government Committee Orientation Day. Winnipeg: OFI.

Peters, E. J. 1994. Aboriginal Self-Government in Urban Areas: Proceedings of a Workshop May 25 and 26. Institute of Intergovernmental Relations: Kingston.

- - - 2005. "Indigeneity and Marginalisation: Planning For and With Urban Aboriginal Communities in Canada." Progress in Planning 63 (4): 327-404. http://dx.doi. org/10.1016/j.progress.2005.03.008.

Royal Commission on Aboriginal Peoples (1993). Integrated Research Plan-Aboriginal Peoples in Urban Centres. Ottawa: Government of Canada.

Taylor, R. 2003. "Indigenous Community Capacity Building and the Relationship to Sound Governance and Leadership." Paper presented at the National Native Title Conference, Alice Springs, Northern Territory, June.

Treasury Board of Canada. 2007 Guidelines for Effective Regulatory Consultations. Ottawa: Treasury Board of Canada. Accessed 10 March 2014. http://www.tbs-sct. gc.ca/rtrap-parfa/erc-cer/erc-certb-eng.asp.

Turnball, L., and P. Aucoin. 2006. Fostering Canadians' Role in Public Policy: A Strategy for Institutionalizing Public Involvement in Policy. Ottawa: Canadian Policy Research Networks. Accessed 10 March 2014. http://www.cprn.org/documents/42670_ en.pdf. 
van den Berg, G. 2009. "The Absence of Democracy in Aboriginal Self-Government Policy." Federal Governance Journal 5 (6). http://library.queensu.ca/ojs/index.php/fedgov/ article/view/4395.

Walker, R. 2005. "Social Cohesion? A Critical Review of the Urban Aboriginal Strategy and its Application to Address Homelessness in Winnipeg." The Canadian Journal of Native Studies 25 (2): 395-416.

Western Economic Diversification Canada (WD). June 2008. "News Releases \$5.6 million Initiative to Return Central Park to Former Glory." Winnpeg: WD. http://www. wd.gc.ca/eng/77_10460.asp.

Wherrett, Jill and Douglas Brown. 1994. "Models for Aboriginal Government in Urban Areas." In Aboriginal Self-Government in Urban Areas: Proceedings of a Workshop May 25 and 26, ed. E. J. Peters, 83-112. Kingston: Institute of Intergovernmental Relations. Accessed 17 March 2014. http://www.queensu.ca/iigr/pub/archive/ aboriginalpapers/misc/AboriginalSelfGovernmentinUrbanAreas.pdf. 